\title{
The Tat pathway in Streptomyces lividans: interaction of Tat subunits and their role in translocation
}

\begin{abstract}
Correspondence
Jozef Anné

Jozef.Anne@rega.kuleuven.be
\end{abstract}

Received 3 October 2006

Revised 12 December 2006

Accepted 15 December 2006

\author{
Sophie De Keersmaeker, Kristof Vrancken, Lieve Van Mellaert, \\ Jozef Anné and Nick Geukens
} Laboratory of Bacteriology, Rega Institute for Medical Research, Katholieke Universiteit Leuven,
Minderbroedersstraat 10, B-3000 Leuven, Belgium

\begin{abstract}
The twin-arginine translocation (Tat) pathway transports folded proteins across bacterial cytoplasmic membranes. The Tat system of Streptomyces lividans consists of TatA, TatB and TatC, unlike most Gram-positive bacteria, which only have TatA and TatC subunits. Interestingly, in $S$. lividans Tat $A$ and TatB are localized in both the cytoplasm and the membrane. In the cytoplasm soluble Tat $A$ and TatB were found as monomers or as part of a hetero-oligomeric complex. Further analysis showed that specific information for recognition of the precursor by the soluble Tat components is mainly present in the twin-arginine signal peptide. Study of the role of the Tat subunits in complex assembly and stability in the membrane and cytoplasm showed that TatB stabilizes TatC whereas a key role in driving Tat complex assembly is suggested for TatC. Finally, by analysis of the oligomeric properties of TatA in the membrane of $S$. lividans and study of the affinity of membrane-embedded TatA for Tat/Sec precursors, a role for TatA as a translocator is postulated.
\end{abstract}

\section{INTRODUCTION}

The twin-arginine translocation (Tat) pathway operates in chloroplast thylakoid membranes and the plasma membrane of many bacteria (reviewed by Robinson \& Bolhuis, 2004). This secretion pathway recognizes substrates that bear cleavable $\mathrm{N}$-terminal signal peptides containing an $\mathrm{S} / \mathrm{T}$ $\mathrm{R}-\mathrm{R}-\mathrm{X}-\phi-\phi$ (where $\phi$ is a hydrophobic residue) consensus sequence that is essential for transport (reviewed by Lee et al., 2006). The overall structure of these N-terminal signal peptides is very similar to the well-characterized signal peptides that are recognized by Sec-type protein translocases. However, the Tat system differs from the Sec pathway in its ability to catalyse the translocation of proteins that have already obtained some degree of tertiary structure in the cytoplasm prior to export. Available evidence suggests that three Tat subunits are involved in this pathway in Gram-negative bacteria, TatA, TatB and TatC (Oates et al., 2003). Tat $A$ and TatB are sequence-related proteins that perform distinct functions in the Tat system (Sargent et al., 1999). Recently, a combination of protein purification studies and in vitro cross-linking work has provided clues to the operating mechanism and suggested that the Tat preprotein first binds to a receptor complex containing TatB and TatC (de Leeuw et al., 2002; Alami et al., 2003).

Abbreviations: EDC/NHS, $N$-(3-dimethylaminopropyl)- $N$ '-ethylcarbodiimide/N-hydroxysuccinimide; GST, glutathione-S-transferase; SAM, self-assembled monolayer; SPR, surface plasmon resonance; Tat, twin-arginine translocation.
After interacting with the primary recognition component TatC, the signal peptide seems to be transferred via TatB to the actual translocation pore, presumably consisting of multiple copies of TatA. Recruitment of TatA to form an active translocation pore is dependent on the presence of the substrate and a proton-motive force (Alami et al., 2003). After completion of protein transport, the TatABCsubstrate complex dissociates and returns to its initial resting conformation.

Recently, three genes encoding homologues of Escherichia coli TatA, TatB and TatC were identified in the genome of Streptomyces lividans. The functionality of the S. lividans Tat pathway has been demonstrated by showing that transport of XlnC and Streptomyces antibioticus tyrosinase was blocked in a tatC deletion mutant (Schaerlaekens et al., 2001). Systematic analysis of these Tat components showed that TatA and TatB, but not TatC, are individually dispensable for Tat-dependent secretion in S. lividans. Although these results suggest that TatA and TatB share functional similarities, different functions were also identified among these proteins (De Keersmaeker et al., 2005b).

Interestingly, besides being membrane-associated proteins, S. lividans TatA and TatB were also detected in the cytoplasm, unlike their E. coli counterparts (De Keersmaeker et al., 2005a). Previously, we reported on structural organization of the membrane-embedded Tat proteins in S. lividans (De Keersmaeker et al., 2005a). The question of whether soluble Tat components participate in Tat 
complexes still had to be addressed. Here, we describe the purification and subsequent characterization of Tat complexes in the cytoplasm of S. lividans wild-type. In addition, the role of each Tat component in the assembly and stability of $S$. lividans Tat complexes in the membrane as well as in the cytoplasm was analysed.

The dual localization of TatA and TatB suggests a role in preprotein targeting to the translocase and a role in preprotein translocation across the cytoplasmic membrane. Here, we analysed the involvement of these proteins in both processes. Therefore, we studied their capacity to specifically interact with signal peptides of Tat-dependent proteins. In addition, the role of membrane-embedded TatA as the protein-conducting channel, as already observed in E. coli (Gohlke et al., 2005), was investigated.

\section{METHODS}

Strains, media and growth conditions. E. coli strain TG1 was used as the host for cloning purposes (Sambrook et al., 1989). Cultures were grown at $37^{\circ} \mathrm{C}$ (shaken at 300 r.p.m.) in LuriaBertani medium, supplemented with the appropriate antibiotics. $S$. lividans TK24 and its derivatives were precultured in $5 \mathrm{ml}$ phage medium (Korn et al., 1978) supplemented with the appropriate antibiotics and grown at $27^{\circ} \mathrm{C}$ with continuous shaking at 300 r.p.m. for $48 \mathrm{~h}$. After homogenizing the mycelium, the strains were inoculated in liquid NM medium (Van Mellaert et al., 1994). For solid medium, MRYE was used (Anné et al., 1990) supplemented with thiostrepton $\left(50 \mu \mathrm{g} \mathrm{ml}^{-1}\right)$ or kanamycin $\left(50 \mu \mathrm{g} \mathrm{ml}^{-1}\right)$, if applicable. Protoplast formation and subsequent transformation of $S$. lividans were carried out as described previously (Kieser et al., 2000).

DNA manipulations and vector constructions. For all DNA manipulations standard techniques were followed (Sambrook et al., 1989; Kieser et al., 2000). Restriction endonucleases and DNAmodifying enzymes were from Invitrogen and Roche Diagnostics. DNA sequence analysis was carried out by the dideoxy chaintermination method with the Thermo Sequenase Primer Cycle Sequencing Kit with 7-deaza-dGTP (GE Healthcare) on an ALFexpress apparatus (GE Healthcare).

pET3aMatXlnC, used for the overproduction and subsequent purification of C-terminally hexahistidine-tagged mature XlnC in $E$. coli BL21(DE3)pLysS, was constructed by inserting an NdeI-HindIII fragment into the corresponding sites of pET3a. This latter fragment encoding mature XlnC was amplified by PCR in the presence of $10 \%$ DMSO using the plasmid pIJvsixyl (Schaerlaekens et al., 2004) as a template with the primers MatXylCF (5'-TACATATGGCCACTACCATCACC- $3^{\prime}$ ) and MatXylCHisR (5'-TAGGATCCTCAGTGATGGTGGTGATGGTGACCGCTGACCGTGATGTTCG-3'). For the isolation of Tat complexes from the cytoplasm of S. lividans, tatA was tagged at the $3^{\prime}$ end with a sequence encoding decahistidine. Therefore, the $S$. lividans tatA gene was amplified by PCR in the presence of $10 \%$ DMSO with the primers TatAF (5'-ATGTTCGGAAGGCTCGGCGCCC- $\left.3^{\prime}\right)$ and TatARHis (5'-TCAGTGGTGATGATGGTGATGGTGGTGATGGTGGCGCTTGGTCGTGTCCGTCGGC-3') using chromosomal DNA of S. lividans TK24 as a template. After cloning the amplified fragment in pGEM-T Easy, the DNA sequence was verified. Next, the tat $A$ gene was cloned downstream of the $v s i$ promoter by cloning an EcoRI fragment containing the $S$. lividans tatA gene into the corresponding site of pBSvsi (Lammertyn, 2000 ), giving rise to $\mathrm{pBSvsiTatA10His.} \mathrm{The} \mathrm{BamHI-EcoRV} \mathrm{fragment} \mathrm{of}$ this latter vector construct, containing the vsi promoter and the coding sequence of TatA10His, was cloned into pIJ486 (Ward et al., 1986), digested with EcoRI, blunt-ended and digested with BamHI. The resulting vector was designated $\mathrm{pIJ} 486 \mathrm{vsiTatA10His.}$

SDS-PAGE and Western blot analysis. Proteins were separated by SDS-PAGE and as a standard the Precision Plus Protein Standard (All Blue) from Bio-Rad was used. Proteins were visualized by Coomassie brilliant blue or by Western blotting and immunodetection with specific antibodies in combination with a suitable secondary alkaline phosphatase-conjugated antibody (Sigma). Visualization of the immunoreactive bands was performed using the chemiluminescent substrate CDP-Star (Western Star Kit, Tropix) or using the chromogenic substrate solution NBT/BCIP (Roche Diagnostics).

Protein overproduction and purification. TatA and TatB were overproduced as GST fusion proteins as described previously (De Keersmaeker et al., 2005a). Purification of soluble GST-TatA, GSTTatB and membrane-embedded GST-TatA was performed as described by De Keersmaeker et al (2005a, b). Overproduction and purification of the $\mathrm{His}_{6}$-tagged precursor forms of S. lividans xylanase $\mathrm{C}(\mathrm{X} \ln \mathrm{C})$ and $S$. lividans subtilisin inhibitor (Sti-1) was performed under denaturating conditions following Geukens et al. (2006). For the overproduction of $\mathrm{His}_{6}$-tagged mature XlnC, E. coli BL21(DE3)pLysS cells were transformed with the expression plasmid pET3aMatXlnC, grown at $37^{\circ} \mathrm{C}$ and induced with $1 \mathrm{mM}$ IPTG as described by Studier et al., (1990). Subsequently, the cultures were grown at $37^{\circ} \mathrm{C}$ for an additional $4 \mathrm{~h}$. E. coli cells producing $\mathrm{His}_{6^{-}}$ tagged mature $\mathrm{XlnC}$ were harvested by centrifugation $(10 \mathrm{~min}$, $5000 \mathrm{~g}, 4{ }^{\circ} \mathrm{C}$ ) and resuspended in $25 \mathrm{ml}$ lysis buffer containing $50 \mathrm{mM} \mathrm{NaH}{ }_{2} \mathrm{PO}_{4} \mathrm{pH} 8.0,300 \mathrm{mM} \mathrm{NaCl}$. Cells were lysed by passing the cells three times through a French pressure cell at $69 \mathrm{MPa}$ and $1 \%$ Triton X-100 was added to the lysate obtained for solubilization. After $30 \mathrm{~min}$ of mixing at $4{ }^{\circ} \mathrm{C}$, samples were cleared by centrifugation $\left(20 \mathrm{~min}, 12000 \mathrm{~g}, 4{ }^{\circ} \mathrm{C}\right)$. Subsequently, the lysate was subjected to a pre-equilibrated $5 \mathrm{ml} \mathrm{Ni}^{2+}$-NTA column. The column was washed with $5 \mathrm{ml}$ solubilization buffer containing $10 \mathrm{mM}$ and $20 \mathrm{mM}$ imidazole, successively. Finally, His $_{6}$-tagged mature XlnC was eluted with $10 \mathrm{ml}$ solubilization buffer containing $100 \mathrm{mM}$ imidazole. The fractions obtained were screened for the presence of mature XlnC using SDS-PAGE and Coomassie brilliant blue staining and immunoblotting with specific $\mathrm{X} \operatorname{lnC}$ antibodies.

Purification of Tat complexes from the membrane and the cytoplasm of S. lividans. S. lividans wild-type and single tat mutants were precultured in $5 \mathrm{ml}$ phage medium for $48 \mathrm{~h}$. Two millilitres of fragmented preculture was used to inoculate $100 \mathrm{ml}$ NM medium, which was subsequently incubated for $24 \mathrm{~h}$. Next, the mycelium was harvested by centrifugation and cells were lysed in a French pressure cell. Cell membrane fractions were then collected by ultracentrifugation $\left(2 \mathrm{~h}, 100000 \mathrm{~g}, 4^{\circ} \mathrm{C}\right)$.

Tat complexes were isolated from the cytoplasmic and membrane fraction of S. lividans wild-type and single tat mutants using chromatographic techniques as described previously (De Keersmaeker et al., 2005a). The presence of Tat $A B$ complexes in the cytoplasm was also investigated using an alternative purification strategy. To this end, C-terminally $\mathrm{His}_{10}$-tagged TatA was overproduced in S. lividans $\Delta$ tatA from the plasmid pIJ486vsiTatA10His. S. lividans $\Delta$ tatA [pIJ486vsiTatA10His] was precultured in $5 \mathrm{ml}$ phage medium for $48 \mathrm{~h}$. Then $100 \mathrm{ml} \mathrm{NM}$ medium was inoculated with $2 \mathrm{ml}$ homogenized preculture and grown for $24 \mathrm{~h}$. The culture was then centrifuged $\left(10 \mathrm{~min}, 5000 \mathrm{~g}, 4{ }^{\circ} \mathrm{C}\right)$ and the cytoplasmic fraction isolated from the collected mycelium as described previously (Geukens et al., 2001). Next, the cytoplasmic proteins were subjected to a preequilibrated $5 \mathrm{ml} \mathrm{Ni}^{2+}$-NTA column. The column was washed with $5 \mathrm{ml}$ solubilization buffer $\left(50 \mathrm{mM} \mathrm{NaH}_{2} \mathrm{PO}_{4} \mathrm{pH} 8.0,300 \mathrm{mM} \mathrm{NaCl}\right)$ containing $10 \mathrm{mM}$ and $20 \mathrm{mM}$ imidazole, successively. Finally, $\mathrm{His}_{10^{-}}$ tagged TatA was eluted with $10 \mathrm{ml}$ solubilization buffer containing 
$100 \mathrm{mM}$ imidazole. The obtained TatA-containing fractions were then tested for the presence of TatB by Western blotting. Fractions enriched in TatA and TatB were pooled, concentrated using a Vivaspin concentrator (Vivascience) and transferred to the gel-filtration buffer ( $50 \mathrm{mM} \mathrm{NaH}_{2} \mathrm{PO}_{4} \mathrm{pH} 7.0,150 \mathrm{mM} \mathrm{NaCl}, 0.2 \%$ Triton X-100) using gel filtration on a PD-10 column (GE Healthcare). The concentrated sample was finally applied to a pre-equilibrated HiPrep Sephacryl S-300/S-200 HR gel-filtration column (GE Healthcare) to determine the molecular mass of the eluted cytoplasmic Tat $A B$ complexes. Protein elution was followed by monitoring the $A_{280}$. Eluted fractions were TCA precipitated (10\% final concentration) and screened for the presence of Tat components by SDS-PAGE and Western blotting using Tat antibodies. Elution positions of marker proteins (HMW Gel Filtration Calibration Kit, GE Healthcare) were used to estimate the molecular mass of eluted Tat complexes.

Surface plasmon resonance experiments. In order to analyse the interaction between membrane-embedded TatA and precursors via surface plasmon resonance (SPR), TatA was immobilized on a biosensor chip, placed in a Biacore2000 apparatus and activated using $N$-(3-dimethylaminopropyl)- $N$-ethylcarbodiimide/ $N$-hydroxysuccinimide (EDC/NHS). Covalent immobilization of membraneembedded GST-TatA on a self-made mixed self-assembled monolayer (SAM) surface (on a J1-chip from Biacore) was accomplished via coupling of the primary amines to the carboxyl group of the SAM surface. During the immobilization protocol a continuous flow $\left(5 \mu \mathrm{min}^{-1}\right.$ ) of $10 \mathrm{mM}$ HEPES $\mathrm{pH} 9.0,0.5 \%$ Triton X-100 (running buffer) was maintained. Injection of a $1: 1$ mixture of $200 \mathrm{mM}$ EDC and $50 \mathrm{mM}$ NHS in deionized water for $10 \mathrm{~min}$ activated the carboxyl groups of the surface layer of the chip. Next, purified membrane-localized GST-TatA $(2 \mu \mathrm{M})$ in $10 \mathrm{mM}$ sodium acetate $\mathrm{pH} 4.0$ was injected, followed by injection of $1 \mathrm{M}$ ethanolamine $\mathrm{pH} 8.5$ over $10 \mathrm{~min}$ in order to block the remaining activated surface groups and to reduce non-covalent association of GST-TatA onto the surface. Finally, all non-covalently bound molecules were removed by injecting $10 \mathrm{mM}$ glycine ( $\mathrm{pH} 2.2$ ) twice for $2 \mathrm{~min}$. A control surface was prepared by running only the activation, deactivation and regeneration procedures. Purified preproteins were perfused over the immobilized TatA surface at a flow rate of $20 \mu \mathrm{min}^{-1}$. After $135 \mathrm{~s}$ of association, the preprotein sample was replaced by running buffer for $300 \mathrm{~s}$, allowing the complex to dissociate. Two pulses of $10 \mathrm{mM}$ glycine ( $\mathrm{pH} 2.2)$ were used for regeneration of the surface. The sensorgrams were corrected for bulk effects and non-specific adsorption to the biosensor surface. Preparation of overlay plots and curve fitting was performed using the BIAevaluation software (Biacore).

\section{RESULTS}

\section{Soluble Tat components participate in hetero-oligomers in the cytoplasm of S. lividans}

Previously, it was shown that three different Tat complexes were present in the cytoplasmic membrane of S. lividans wild-type (De Keersmaeker et al., 2005a). Firstly, a complex in which all Tat components participate, a Tat $\mathrm{ABC}$ complex, was purified, with a molecular mass of about $585 \mathrm{kDa}$. Next, a (200-400 kDa) complex containing only TatA and TatB was present in membrane fractions together with separate TatA complexes with sizes ranging from below $100 \mathrm{kDa}$ to over $600 \mathrm{kDa}$. In order to investigate whether soluble TatA and TatB are present in the cytoplasm as a part of a complex, we isolated the cytoplasmic fraction of S. lividans wild-type. The subcellular localization of SipW, a type I signal peptidase of S. lividans with similar topology to TatA/B, was taken as a control to assess the quality of fractionation and to ensure that the cytoplasmic fraction was not contaminated with membrane proteins (data not shown). The cytoplasmic fraction obtained containing TatA and TatB was then subjected to ion-exchange and gel-filtration chromatography as described previously (De Keersmaeker et al., 2005a) in order to investigate the structural organization of soluble TatA and TatB in S. lividans. The TatA-mediated purification strategy demonstrated that TatA could be present in the cytoplasm as oligomers and monomers. More specifically, TatA could be detected in elution fractions corresponding to a molecular mass varying from below $100 \mathrm{kDa}$ to over $600 \mathrm{kDa}$ (data not shown). Immunoblotting with TatB antibodies showed the presence of TatB in all TatA-containing samples, strongly suggesting that TatA and TatB form hetero-oligomeric complexes in the cytoplasm. Also, via the TatB-mediated purification strategy, evidence for a cytoplasmic TatAB complex was obtained. Because of the very low levels of TatA and TatB in the final elution samples, we do not know whether TatA actually co-purifies with the TatB protein or with another protein which can bind the anion/cation-exchange column under these conditions. To rule out the latter possibility, a different approach was used to investigate cytoplasmic TatA-TatB interaction. In particular, we investigated the nature and the size of cytoplasmically localized Tat complexes that could be purified from an S. lividans strain containing carboxy-terminally $\mathrm{His}_{10}{ }^{- \text {tagged TatA. To }}$ construct this strain, the coding sequence of S. lividans TatA was amplified by PCR (the decahistidine-encoding sequence was incorporated in the $3^{\prime}$ primer) and the amplified DNA sequence was cloned downstream of the strong constitutive promoter of the vsi gene (Lammertyn et al., 1997) on pIJ486 (Ward et al., 1986). Finally, S. lividans $\Delta$ tatA protoplasts were transformed with the resulting plasmid pIJ486vsiTatA10His. From this strain, cytoplasmic proteins were isolated and loaded onto a $\mathrm{Ni}^{2+}$-affinity column. The TatA10His protein specifically bound to this column. After screening the elution fractions by Western blot analysis with TatA- and TatB-specific antibodies, TatB was found to coelute with the TatA10His protein (Fig. 1), giving strong evidence for direct TatA-TatB interaction in the cytosol. Subsequent gel-filtration chromatography showed that the Tat $A B$ complexes that bind to the $\mathrm{Ni}^{2+}$-affinity column have an apparent molecular mass ranging from below $100 \mathrm{kDa}$ to over $600 \mathrm{kDa}$, which is consistent with the data described above. Taken together, these data firmly indicate the existence of a hetero-oligomeric Tat $\mathrm{AB}$ complex in the cytoplasm of $S$. lividans.

\section{Isolation of Tat complexes from S. lividans single tat mutants}

The fact that Tat complexes could be isolated when expressed at wild-type levels enabled us to study the role of each Tat component in the assembly and stability of Tat complexes, more specifically by comparing the nature and 
123

TatA

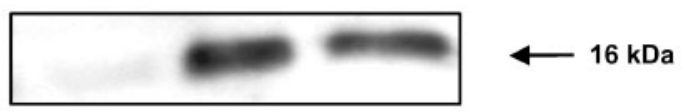

TatB

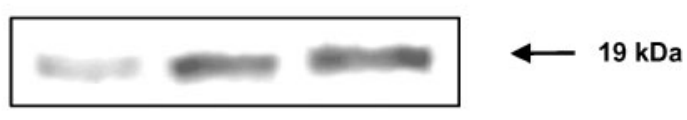

Fig. 1. Identification of a Tat $A B$ complex. Cytoplasmic proteins isolated from $S$. lividans $\triangle$ tat $A$ harbouring plJ486vsiTatA10His were applied to a $\mathrm{Ni}^{2+}$-affinity column. The elution fractions (lanes $1-3$ ) of the $\mathrm{Ni}^{2+}$-affinity column were analysed by SDSPAGE and Western blotting with antibodies against TatA and TatB. The molecular mass is indicated in $\mathrm{kDa}$. size of Tat complexes from single tat mutants with those present in the wild-type. It should be noted that in E. coli Tat complexes could only be isolated when the tat operon was overexpressed.

Isolation of Tat complexes from the cytoplasmic membrane. We used the same chromatographic techniques to study the properties of the purified Tat complexes in the membrane of the $S$. lividans single tat deletion strains as used to study Tat complex formation in the wild-type (Fig. 2a).

Firstly, the effect of deletion of tatA on Tat complex formation in the membrane of $S$. lividans was addressed by subjecting solubilized membranes isolated from an $S$. (a)
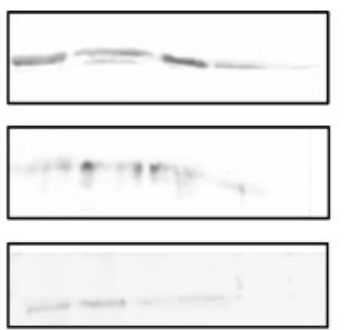

$\begin{array}{llllllll}48 & 50 & 52 & 54 & 56 & 58 & 60 & 62\end{array}$

$669 \mathrm{kDa}$

(b)
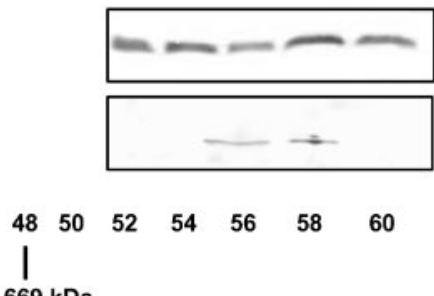

$669 \mathrm{kDa}$

(c)
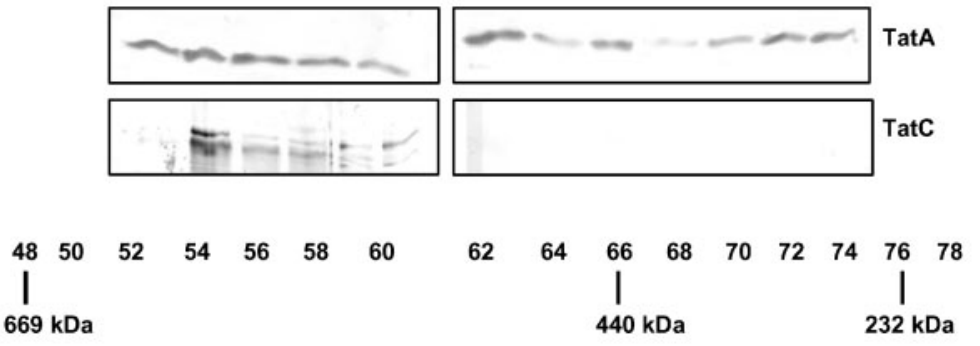

(d)
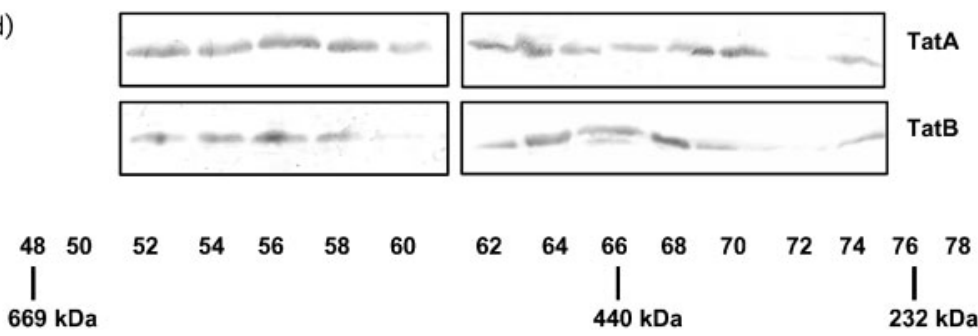

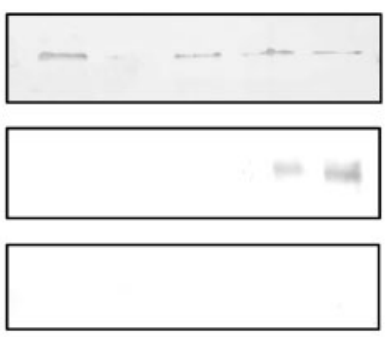

TatA

TatB

TatC
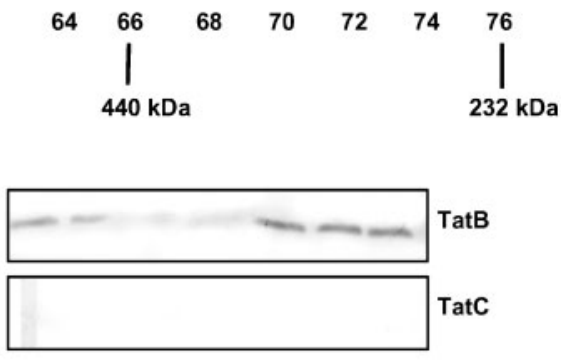

6264

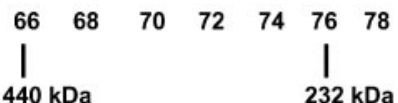

Fig. 2. Purification of Tat complexes. Solubilized membrane proteins from $S$. lividans wild-type (a) and single $\operatorname{tat} A(\mathrm{~b})$, tat $B$ (c) and tatC (d) deletion strains were applied to an ion-exchange column. Tatcontaining fractions were pooled, concentrated and subjected to gel-filtration chromatography on a Sephacryl S-300 column. The eluted fractions, precipitated with 10\% TCA, were screened for the presence of TatA, TatB and TatC by SDS-PAGE and Western blotting using Tat-specific antisera. The lane numbers below the immunoblots correspond to the fraction number of the elution profile. The elution positions of water-soluble standard proteins are shown below the fraction numbers. Standard proteins used are thyroglobulin $(669 \mathrm{kDa})$, ferritin $(440 \mathrm{kDa})$ and catalase $(232 \mathrm{kDa})$. 
lividans single tatA mutant to anion-exchange chromatography followed by gel filtration on a calibrated Sephacryl S-300 column. Western blot analysis showed that TatC elutes together with some TatB in fractions that correspond to a molecular mass of approximately $600 \mathrm{kDa}$ (Fig. 2b). Surprisingly, TatB was invariably found to elute over a wide range of gel filtration fractions as seen in Fig. 2(b). We concluded that in the absence of TatA, TatB and TatC are still present in a high molecular mass complex with an observed size similar to that of the wild-type core complex, TatABC. In addition, homo-oligomeric TatB complexes were identified in the membrane of the S. lividans $\Delta$ tatA mutant, with sizes ranging from about $200 \mathrm{kDa}$ to over $600 \mathrm{kDa}$ (Fig. 2b). When a calibrated Sephacryl S-200 column was used, TatB complexes with a molecular mass between $200 \mathrm{kDa}$ and approximately $100 \mathrm{kDa}$ could be detected (data not shown).

To analyse the influence of TatB on Tat complex formation, we solubilized membranes of an $S$. lividans single tat $B$ mutant and subjected the clarified membrane extracts to cation-exchange and subsequent gel-filtration chromatography. Analysis of the eluted fractions by Western blotting with Tat-specific antibodies showed that Tat A and TatC coeluted in a broad peak, corresponding to a molecular mass of about $600 \mathrm{kDa}$ (Fig. 2c). In addition, Western blot analysis revealed some degradation products of the TatC protein, as shown clearly in Fig. 2(c). These results suggested that TatC stability is highly dependent on the presence of TatB. As shown in Fig. 2(c), TatA was consistently observed to elute in a wide range of fractions ranging in size from approximately $200 \mathrm{kDa}$ to over $600 \mathrm{kDa}$. In addition, TatA complexes with a molecular mass between $200 \mathrm{kDa}$ and approximately $100 \mathrm{kDa}$ could be detected when a calibrated Sephacryl S-200 column was used (data not shown).

As observed for the TatBC complex, the size of the TatAC complex fits well with the size estimates for the wild-type TatABC complex. These results suggest that deletion of the TatB component has no effect on Tat complex assembly. However, since some proteolytic breakdown of the TatC subunit was observed within the complex in the absence of $\mathrm{Tat} B$, a role in stabilizing TatC is suggested.

Finally, our data provided evidence that in a strain lacking the TatC component, Tat $\mathrm{A}$ and $\mathrm{Tat} \mathrm{B}$ do not co-elute in one single peak corresponding to a molecular mass of about $600 \mathrm{kDa}$ (Fig. 2d). Instead Tat AB complexes were found to elute over a wide range of fractions with corresponding molecular masses of over $600 \mathrm{kDa}$ to less than $100 \mathrm{kDa}$. Taking the data together, we have shown that in the absence of TatC, the assembly of one specific Tat complex with a size of $\sim 585 \mathrm{kDa}$ does not occur, demonstrating a key role for TatC in driving Tat complex assembly.

Isolation of Tat complexes from the cytoplasm. To determine whether the soluble Tat components were still participating in Tat complexes in the absence of one of the key Tat subunits, we attempted to identify and characterize
Tat complexes in the cytoplasm of S. lividans single tatA, tat $B$ and tat $C$ deletion strains. Isolated cytoplasmic proteins of the respective S. lividans single tat mutants were analysed using ion-exchange columns followed by gel-filtration chromatography and the nature and size of these cytoplasmic Tat complexes was determined. In the absence of TatA, Western blot analysis revealed that part of TatB was present as monomer, whereas the majority of TatB self-assembled into complexes with a molecular mass ranging from below $100 \mathrm{kDa}$ to over $600 \mathrm{kDa}$. In the absence of TatB, TatA was characterized by a similar elution profile to that of TatB. Besides the monomeric form of TatA, homo-oligomeric TatA complexes could be identified in the cytoplasm of an $S$. lividans tatB deletion strain. Finally, in the absence of the TatC component, Western blot analysis showed that TatB is associated with TatA, constituting hetero-oligomeric TatAB complexes with a varying molecular mass from below $100 \mathrm{kDa}$ to over $600 \mathrm{kDa}$ (data not shown).

\section{Soluble Tat components bind to the signal peptide of Tat-dependent preproteins}

The ability of soluble TatA/B proteins to bind purified Tat precursors has recently been reported (De Keersmaeker et al., 2005b). However, these experiments did not give any information about the exact region of the Tat preprotein substrates recognized by the soluble Tat proteins. If soluble Tat $\mathrm{A}$ and $\mathrm{Tat} \mathrm{B}$ are involved in targeting Tat-dependent substrates to the translocase, one would expect that they bind the twin-arginine signal peptide, an important determinant of targeting information. To this end, the particular role of the Tat signal peptide in mediating binding of the substrate to the soluble Tat components was studied. Therefore, the affinity of both soluble TatA and TatB for the mature part and the precursor form of the Tat substrate $\mathrm{XlnC}$ was analysed using SPR. $\mathrm{His}_{6}$-tagged mature $\mathrm{XlnC}$ and XlnC precursor together with the soluble GST-tagged TatA and TatB proteins were individually overproduced in E. coli and purified as described in Methods. Different concentrations of purified mature $\mathrm{X} \ln C$ and precursor preXlnC were flowed continuously $\left(20 \mu \mathrm{min}^{-1}\right)$ over the immobilized soluble GST-tagged S. lividans TatA and TatB surfaces. Curve fitting of the response curves using BIAevalution software revealed the observed rates during association and dissociation of the interactions of each soluble Tat component to the mature part of XlnC and preXlnC. In both cases, the soluble Tat component recognized preXlnC with a much higher affinity than mature XlnC (data not shown). In more detail, the interaction of preXlnC with TatA was characterized by a $K_{\mathrm{D}}$ of $37.8 \pm 4.7 \mathrm{nM}$, whereas binding of mature XlnC to soluble TatA had a $K_{\mathrm{D}}$ of $69.3 \pm 6.6 \mu \mathrm{M}$, demonstrating selective affinity of soluble TatA for preXlnC, containing a twin-arginine signal peptide. Similar data were obtained for soluble TatB. It should also be noted that the binding affinity of a typical Sec-dependent preprotein Sti-1 to soluble TatA/B was 1000-fold less than observed for preXlnC $\left(K_{\mathrm{D}} \quad 16.0 \pm 5.0 \mu \mathrm{M}\right)$. The fact that 
soluble Tat $\mathrm{A}$ and TatB preferentially bind preXlnC suggests that the specific information necessary for recognition by the soluble Tat components is mainly present in the twinarginine signal peptide. Attempts to narrow down this region to the twin-arginine motif of the signal peptide are a future line of enquiry.

\section{Membrane-embedded TatA has affinity for Tat precursors}

Previous analyses showed the presence of separate homooligomeric TatA complexes ranging in size from below $100 \mathrm{kDa}$ to over $600 \mathrm{kDa}$ in S. lividans wild-type which could be indicative of a role of the TatA component in the formation of a protein-conducting channel in S. lividans, as already observed in E. coli. Here, the homo-oligomeric TatA complexes present in the cytoplasmic membrane were of different sizes but were all similar in shape, resembling a ring with an asymmetric lid at one end (Gohlke et al., 2005). The difference in sizes is most likely due to a difference in number of TatA molecules present in the complex. Since the substrates to be transported are of highly variable size, we speculate that the TatA protein will match the size of the channel to prevent proton leakage.

A prerequisite for TatA to fulfil a function as translocator would be the interaction of membrane-integrated TatA with a Tat precursor (Schreiber et al., 2006). To analyse this, we used SPR to study the bimolecular interaction of membrane-embedded TatA and the Tat precursor preXlnC. In addition, we tried to determine whether, if a Sec-dependent protein reached the Tat translocase, it could get translocated efficiently. For this, it should be able to interact efficiently with membrane-embedded TatA. To examine this, a kinetic analysis was done to determine the affinity of membranebound TatA for the Tat- and Sec-dependent precursors, preXlnC and preSti-1, respectively. Therefore, purified GST-TatA was covalently immobilized on a biosensor chip and different concentrations of purified preXlnC and preSti-1 (overproduction and purification is described in detail in Methods) were flowed over this surface. The binding curves generated were put in an overlay plot used for curve fitting by the BIAevaluation software. Interaction of preXlnC with membrane-embedded TatA was characterized by an apparent $K_{\mathrm{D}}$ of $25.7 \pm 9.4 \mathrm{nM}$ whereas a $K_{\mathrm{D}}$ of $44.6 \pm 9.5 \mu \mathrm{M}$ was observed for the binding of preSti-1 to membrane-embedded TatA. As such, the affinity of membrane-embedded TatA for preXlnC was of the same order of magnitude as that of soluble TatA for preXlnC. The low efficiency of Sec-dependent substrate recognition by membrane-embedded TatA together with the fact that the soluble Tat components preferentially bind Tat-dependent preprotein substrates (De Keersmaeker et al., 2005b) strongly suggests that the Tat system in S. lividans can actively discriminate between Sec- and Tat-dependent preproteins and is specifically engaged in the recognition and translocation of Tat-dependent proteins.

\section{DISCUSSION}

Initial characterization of the Tat pathway in $S$. lividans revealed a dual localization of TatA and TatB, both as membrane-associated and as soluble proteins (De Keersmaeker et al., 2005a). Transport systems with soluble Tat proteins might therefore act fundamentally differently from the well-characterized Tat pathway of $E$. coli, for which no soluble Tat components have been detected to date. Data support preprotein targeting as a function for the soluble Tat components in S. lividans based on striking analogies with the Bacillus subtilis system, in which soluble TatAd is engaged in preprotein targeting of PhoD (Pop et al., 2003). Previous data showed that both cytoplasmic TatA and TatB specifically recognize the Tat-dependent preproteins preXlnC and preMelC1 in the absence of other Tat components. Furthermore, it was shown that soluble TatA and B have affinity for the exclusively membrane-embedded TatC protein, which most likely makes up or at least is part of the docking site for the soluble Tat proteins (De Keersmaeker et al., 2005b). In the present work, the interaction between soluble Tat components and Tat-dependent substrates was analysed in more detail. We observed that soluble TatA and TatB preferentially bind to the signal peptide of the Tat substrate, indicating that the primary recognition site for soluble TatA/B binding is situated in the signal peptide. It is very likely that the twin-arginine motif at the border of the $\mathrm{n}$ - and h-region of the signal peptide is the target site of soluble TatA/B. However, the latter has not yet been demonstrated experimentally, but will be studied in the near future. Nevertheless, we observed weak binding of soluble TatA/B to the mature part of the Tat substrate, indicating that secondary, but obviously less important, binding sites might be present in this region. Our findings are fully consistent with the B. subtilis system, where it was shown that the twinarginine signal peptide of prePhoD is the target site for soluble TatAd (Pop et al., 2003). Here, co-immunoprecipitation experiments on TatAd with peptides derived from the PhoD signal peptide further demonstrated that the twinarginine motif was the target site for TatAd interaction (Pop et al., 2003). Interestingly, our data demonstrated that soluble TatA and TatB proteins can separately bind Tat substrates with similar affinities. However, in this work we have shown that TatA and TatB participate in heterooligomers in the cytoplasm. The in vivo significance of the in vitro interaction data is therefore not clear yet. Two possibilities are considered: (1) TatA and TatB interact with the protein and recognize either the same or a different region of the signal peptide; (2) either TatA or TatB interacts in vivo with the Tat substrate. Very recently, it was reported that B. subtilis TatA molecules are organized as cylindermicelle-like structures with a $120 \AA$ hydrophobic centre, which could accommodate an $\alpha$-helical domain of a signal peptide (Westermann et al., 2006). As we have observed hetero-oligomerization of TatA and TatB in the cytoplasm of S. lividans, it is very likely that they are organized in similar structures. In this line of research, future work will be 
focussed at defining the exact binding site of soluble Tat $\mathrm{AB}$ on the preprotein and investigating if these Tat $A B$ heterodimers in vivo are organized in high molecular mass complexes before binding Tat-dependent preproteins, as observed in B. subtilis.

From the membrane of $S$. lividans different Tat complexes of similar size and composition to those in E. coli membranes were purified (De Keersmaeker et al., 2005a). In addition to a $585 \mathrm{kDa}$ complex in which all Tat subunits participate, a TatAB complex with varying size between 200 and $400 \mathrm{kDa}$ and homo-oligomeric TatA complexes ranging from below $100 \mathrm{kDa}$ to over $600 \mathrm{kDa}$ could be isolated. Analysis of Tat complexes in the membrane of $S$. lividans single tat mutants provided us with more details about the driving forces for assembly and maintenance of the TatABC complex. As in $E$. coli, TatC was found to be the driving force for the assembly of the core complex, while TatB was found to be important in the stability and maintenance of this complex, since its absence resulted in specific breakdown of TatC. It is speculated that $\mathrm{Tat} B$ through binding to Tat $\mathrm{C}$ might act as a connecting link, stabilizing the interaction of the receptor $\mathrm{TatC}$ with the soluble precursor-Tat complex or facilitating recruitment of TatA complexes to this precursor-bound Tat complex to form the active TatABC translocase complex. If so, in the absence of TatB, the pore might assemble inefficiently around $\mathrm{Tat} C$, hampering protein translocation.

Finally, the in vitro experiments showed binding of Tat substrates to TatA in its membrane-embedded localization, which could be indicative that TatA fulfils a central role in the formation of the translocation channel in the membrane of S. lividans. Binding of membrane-embedded TatA to Tat substrates seems to occur without the requirement for other Tat components and the proton-motive force, although their presence is likely to stabilize the interaction. Taking into account that TatA protomers are found in separate homo-multimeric assemblies of varying size in the membrane of S. lividans and that $\mathrm{TatC}$ is not a prerequisite for TatA homo-oligomerization, it is tempting to speculate that this organization of TatA provides the flexibility to respond to the wide range of folded proteins to be transported by the Tat system of S. lividans. The function of TatA as being involved in pore formation and mediating transport of its Tat substrate across the cytoplasmic membrane seems to be very conserved in S. lividans, E. coli and B. subtilis. In E. coli and B. subtilis, a spectrum of TatA complexes forming ringlike structures in the membrane (Gohlke et al., 2005; Westermann et al., 2006) has been reported as well as the colocalization of Tat precursors with membrane-integrated TatA (Alami et al., 2003; Westermann et al., 2006). In addition, cross-complementation tests recently revealed that Streptomyces coelicolor TatA protein supports a high level of Tat activity in an E. coli double tatA/E mutant. These results suggest that $S$. coelicolor TatA would self-oligomerize into channel-forming multimers mediating transport of Tat substrates (Hicks et al., 2006).
According to our previous findings and the data described above, the Tat system in S. lividans is functionally different from the E. coli TatABC system. Although a recent report suggested a rather similar Tat transport system in both organisms, following the observation that heterologously expressed S. coelicolor TatA was functional in E. coli and was found only in the membrane fraction of E. coli (Hicks et al., 2006), we believe, based on our results demonstrating the presence of soluble forms of Tat $\mathrm{A}$ and Tat $\mathrm{B}$, in a model in which soluble Tat $\mathrm{A}$ and $\mathrm{Tat} \mathrm{B}$, associated with each other, are involved in preprotein targeting. After recognition and binding of the substrate, the Tat $A B$ complex brings the substrate directly to TatC, which mediates insertion of the precursor-Tat complex into the membrane. Finally, after reorganization of the Tat components in the cytoplasmic membrane, the precursor-Tat complex triggers the recruitment of a separate TatA complex to form a functional TatABC-containing translocation system allowing export of the Tat substrate. This association would be transient, being lost once the substrate is translocated, suggesting that transport of Tat substrates by the Tat pathway is a dynamic event that involves reversible association of separate subcomplexes of Tat components.

\section{ACKNOWLEDGEMENTS}

This work was supported by grants QLK-2000-00122 and ETC-B1068QLK3-CT-2002-02056 from the European Union and FWO grant G.0389.05. S.D. K. and K.V. are research fellows of IWT (Vlaams Instituut voor de bevordering van het Wetenschappelijk-Technologisch onderzoek in de industrie).

\section{REFERENCES}

Alami, M., Luke, I., Deitermann, S., Eisner, G., Koch, H., Brunner, J. \& Muller, M. (2003). Differential interactions between a twin-arginine signal peptide and its translocase in Escherichia coli. Mol Cell 12, 937-946.

Anné, J., Van Mellaert, L. \& Eyssen, H. (1990). Optimum conditions for efficient transformation of Streptomyces venezuelae protoplasts. Appl Microbiol Biotechnol 32, 431-435.

De Keersmaeker, S., Van Mellaert, L., Schaerlaekens, K., Van Dessel, W., Vrancken, K., Lammertyn, E., Anné, J. \& Geukens, N. (2005a). Structural organization of the twin-arginine translocation components in the Gram-positive Streptomyces lividans. FEBS Lett 579, 797-802.

De Keersmaeker, S., Van Mellaert, L., Lammertyn, E., Vrancken, K., Anné, J. \& Geukens, N. (2005b). Functional analysis of TatA and TatB in Streptomyces lividans. Biochem Biophys Res Commun 335, 973-982.

de Leeuw, E., Granjon, T., Porcelli, I., Alami, M., Carr, S., Muller, M., Sargent, F., Palmer, T. \& Berks, B. (2002). Oligomeric properties and signal peptide binding by Escherichia coli Tat protein transport complexes. J Mol Biol 322, 1136-1146.

Geukens, N., Lammertyn, E., Van Mellaert, L., Schacht, S., Schaerlaekens, K., Parro, V., Bron, S., Engelborghs, Y., Mellado, R. \& Anné, J. (2001). Membrane topology of the Streptomyces lividans type I signal peptidases. J Bacteriol 183, 4752-4760. 
Geukens, N., Rao C. V., S., Mellado, R., Frederix, F., Reekmans, G., De Keersmaeker, S., Vrancken, K., Bonroy, K., Van Mellaert, L. \& other authors (2006). Analysis of type I signal peptidase specificity in Streptomyces lividans reveals competition for binding preprotein substrates. Microbiology 152, 1441-1450.

Gohlke, U., Pullan, L., McDevitt, C., Porcelli, I., de Leeuw, E., Palmer, T., Saibil, H. \& Berks, B. (2005). The TatA component of the twin-arginine protein transport system forms channel complexes of variable diameter. Proc Natl Acad Sci U S A 102, 10482-10486.

Hicks, M., Guymer, D., Buchanan, G., Widdick, D., Caldelari, I., Berks, B. \& Palmer, T. (2006). Formation of functional Tat translocases from heterologous components. BMC Microbiol 6, 64.

Kieser, T., Bibb, M. J., Buttner, M. J., Chater, K. F. \& Hopwood, D. A. (2000). Practical Streptomyces Genetics. Norwich: John Innes Foundation.

Korn, F., Weingärtner, B. \& Kutzner, H. J. (1978). A study of twenty actinophages: morphology, serological relationship and host range. In Genetics of the Actinomycetales, pp. 251-270. Edited by E. Freechsen, I. Tarnak \& J. H. Thumin. Stuttgart: Gustav Fischer.

Lammertyn, E. (2000). Isolation and characterisation of a novel subtilisin inhibitor gene from Streptomyces venezuelae and evaluation of its regulatory sequences for heterologous protein secretion by Streptomyces lividans. $\mathrm{PhD}$ thesis, KU Leuven, Belgium.

Lammertyn, E., Van Mellaert, L., Schacht, S., Dillen, C., Sablon, E., Van Broekhoven, A. \& Anné, J. (1997). Evaluation of a novel subtilisin inhibitor gene and mutant derivatives for the expression and secretion of mouse tumor necrosis factor alpha by Streptomyces lividans. Appl Environ Microbiol 63, 1808-1813.

Lee, P., Tullman-Ercek, D. \& Georgiou, G. (2006). The bacterial twinarginine translocation pathway. Annu Rev Microbiol 60, 373-395.

Oates, J., Mathers, J., Mangels, D., Kühlbrandt, W., Robinson, C. \& Model, K. (2003). Consensus structural features of purified bacterial TatABC complexes. J Mol Biol 330, 277-286.

Pop, O., Westermann, M., Volker-Engert, R., Schulz, D., Lemke, C., Schreiber, S., Gerlach, R., Wetzker, R. \& Muller, J. (2003). Sequencespecific binding of prePhoD to soluble TatAd indicates proteinmediated targeting of the Tat export in Bacillus subtilis. J Biol Chem 278, 38428-38436.
Robinson, C. \& Bolhuis, A. (2004). Tat-dependent protein targeting in prokaryotes and chloroplasts. Biochim Biophys Acta 1694, 135-147.

Sambrook, J., Fritsch, E. F. \& Maniatis, T. (1989). Molecular Cloning: a Laboratory Manual. Cold Spring Harbor, NY: Cold Spring Harbor Laboratory.

Sargent, F., Stanley, N., Berks, B. \& Palmer, T. (1999). Secindependent protein translocation in Escherichia coli: a distinct and pivotal role for the TatB protein. J Biol Chem 274, 36073-36082.

Schaerlaekens, K., Schierová, M., Lammertyn, E., Geukens, N., Anné, J. \& Van Mellaert, L. (2001). Twin-arginine translocation pathway in Streptomyces lividans. J Bacteriol 183, 6727-6732.

Schaerlaekens, K., Van Mellaert, L., Lammertyn, E., Geukens, N. \& Anné, J. (2004). The importance of the Tat-dependent protein secretion pathway in Streptomyces as revealed by phenotypic changes in tat deletion mutants and genome analysis. Microbiology 150, 21-31.

Schreiber, S., Stengel, R., Westermann, M., Volckmer-Engert, R., Pop, O. \& Muller, J. (2006). Affinity of TatCd for TatAd elucidates its receptor function in the Bacillus subtilis twin arginine translocation (Tat) translocase system. J Biol Chem 281, 19977-19984.

Studier, F., Rosenberg, A., Dunn, J. \& Dubendorff, J. (1990). Use of T7 RNA polymerase to direct expression of cloned genes. Methods Enzymol 185, 60-99.

Van Mellaert, L., Dillen, C., Proost, P., Sablon, E., Deleys, R., Van Broekhoven, A., Heremans, H., Van Damme, J., Eyssen, H. \& Anné, J. (1994). Efficient secretion of biologically active mouse tumor necrosis factor alpha by Streptomyces lividans. Gene 150, 153-158.

Ward, J., Janssen, G., Kieser, T., Bibb, M., Buttner, M. \& Hopwood, D. (1986). Construction and characterisation of a series of multi-copy promoter-probe plasmid vectors for Streptomyces using aminoglycoside phosphotransferase gene from Tn5 as indicator. Mol Gen Genet 203, 468-478.

Westermann, M., Pop, O., Gerlach, R., Appel, T., Schlörmann, W., Schreiber, S. \& Muller, J. (2006). The TatAd component of Bacillus subtilis twin-arginine protein transport system forms homo-multimeric complexes in its cytosolic and membrane embedded localisation. Biochim Biophys Acta 1758, 443-451.

Edited by: R. P. Mellado 